\title{
PI3K/AKT Signaling Pathway Mediates the Proliferation, Migration and Invasion of Papillary Craniopharyngioma Cells
}

\section{Lin Zhou}

The First Affiliated Hospital of Nanchang University

\section{Cheng Xing Yang}

The First Affiliated Hospital of Nanchang University

\section{Lin Chun Fang}

The First Affiliated Hospital of Nanchang University

\section{You Yuan Bao}

The First Affiliated Hospital of Nanchang University

\section{Zhi Gang Wang}

The Ninth People's Hospital, Shanghai Jiao Tong University School of Medicine

\section{Shao Yang Li}

The First Affiliated Hospital of Nanchang University

\section{Min De Li}

The First Affiliated Hospital of Nanchang University

Shi Hai Lan

The First Affiliated Hospital of Nanchang University

Xiao Wu

The First Affiliated Hospital of Nanchang University

\section{Zhi Gao Tong}

The First Affiliated Hospital of Nanchang University

\section{Su Yue Zheng}

The First Affiliated Hospital of Nanchang University

\section{Bin Tang}

The First Affiliated Hospital of Nanchang University

Tao Hong ( $\nabla$ ht2000@vip.sina.com )

The First Affiliated Hospital of Nanchang University

\section{Research Article}

Keywords: Craniopharyngiomas, PI3K/Akt signaling pathway, LY294002 
Posted Date: December 10th, 2020

DOI: https://doi.org/10.21203/rs.3.rs-119581/v2

License: (c) (i) This work is licensed under a Creative Commons Attribution 4.0 International License. Read Full License 


\section{Abstract}

Objective:Craniopharyngiomas are rare, histologically benign but clinically challenging neoplasms. Here, we aimed to interrogate the effect and significance of Phosphatidylinositol-3-kinase (PI3K) signaling pathway on papillary craniopharyngioma (PCP) cell growth and survival.

Methods: We used Western blotting (WB) experiments to evaluate the expression of the PI3K/protein kinase B (AKT) in Craniopharyngiomas tissues, relative to health tissues. Primary tumor cells were obtained from fresh PCP samples by cell culture and then determined by cell morphology, immunofluorescence staining and expression of specific cell markers. In this study, PCP cell lines, isolated from fresh PCP samples, were treated with different concentrations of LY294002, a PI3K/AKT signaling inhibitor, to evaluate their proliferation, migration and invasion. We determined the cell proliferation using Cell Counting Kit-8 and colony formation. We then used flow cytometry to evaluate cell apoptosis and cell cycle. In addition, cell migration and invasion levels were determined by wound healing and Transwell assays, respectively.

Results: Our data demonstrated that the expression of phosphorylated-PI3K/AKT was upregulated in human craniopharyngioma tissues compared to the normal control tissues. Immunofluorescence assays showed the presence of cytokeratin (pan CK) and vimentin protein (VIM) in the PCP primary cells. Furthermore, inhibition of PI3K/AKT signaling blocks the proliferation, migration and invasion of the PCP primary cells.

Conclusions:Taken together, our data robustly demonstrates that the PI3K/AKT signaling pathway mediates the proliferation, migration and invasion of the PCP cells.

\section{Introduction}

Craniopharyngiomas are rare tumours with low histological malignancy that arise from cells of the craniopharyngeal duct. The craniopharyngiomas are divided into two histological subtypes, adamantinomatous craniopharyngioma (ACP) and papillary craniopharyngioma (PCP), which differ in genesis and age distribution. Whereas ACPs are diagnosed with a bimodal peak of incidence (5-15 years and $45-60$ years), the PCPs are mainly found in adults[1].

ACP tumorigenesis is characterized by activated Wnt signaling pathway, and accumulation of nuclear b-catenin caused by CTNNB1 gene mutation. The CTNNB1 gene mutations are reported in $16 \%-100 \%$ of the ACP patients [2, 3].In their studies, Tobias Goschzik et al. reported that the CTNNB1 mutations are exclusively localized in exon 3 , which encodes a degradation-targeting box where phosphorylation of Ser45 by casein kinase 1 first occurs. The mutation leads to the phosphorylation of b-catenin which subsequently affects tumor suppression. On the other hand, BRAF V600E mutations were detected in 81$100 \%$ of PCP cases, and the mutation activates the MEK/ERK pathway $[3,4]$. 
During tumorigenesis, tumor cells exploit normal cell-mediated signaling pathways to achieve their own cell proliferation, migration, and anti-apoptosis, thus gaining growth advantages over the normal cells. Some of these signaling pathways are mediated by cell membrane receptors [5]. To date, there are two major types of membrane receptors; the G protein coupled receptors (GPCRs) and receptor tyrosine kinases (RTKs). PI3K is the main downstream effector of both the GPCRs and the RTKs. Membrane receptors mediate the PI3K activation leading to production of a second messenger, phosphatidyl-3,4,5triphosphate (PIP3), on the plasma membrane. The interaction of the PIP3 with the cell membrane via a pleckstrin homology $(\mathrm{PH})$ domain recruits the signal protein Akt and phosphoinositide dependent kinase1 (PDK1). Akt translocates to the cell membrane and gains its catalytic activity. It catalyzes the phosphorylation of its own Ser124 and Thr450. Activation of the Akt by PI3K leads to the phosphorylation of downstream target protein mTOR, forming mTORC1 and mTORC2 complexes[7, 8]. Whereas the mTORC1 promotes protein synthesis and maintains cell metabolism and growth, mTORC2 complex can activate Akt to inhibit the hydrolysis of cyclin D1/E, thus maintaining tumor cell proliferation. A number of studies have indicated that Phosphatase And Tensin Homolog (PTEN) is able to dephosphorylate PIP3, antagonize PI3K activity and reduce the concentration of PIP3 within the cells, thereby inhibiting the activation of Akt and subsequent regulation of cell apoptosis [7]. Besides the PTENmediated apoptosis, the Akt activity can be inhibited by phosphorylation of its downstream target proteins; Bad, Caspase9, NF-kB, FOXP4, P21[7, 9]. Here, we observed increased expression of activated/phosphorylated ( $\mathrm{p}-\mathrm{PI} \mathrm{IK}$ ) and ( $\mathrm{p}-\mathrm{AKT}$ ), in craniopharyngiomas tissues. Treatment with PI3K inhibitor LY294002 weakened the proliferation and migration ability of the PCP cells. Thus, the proliferation, migration and anti-apoptosis nature of the craniopharyngioma cells are related to the activation of the PI3K-Akt signaling pathway.

\section{Methods}

\section{Patients and sample collection}

Surgically excised craniopharyngiomas and healthy brain tissue samples were collected from Nanchang University (Nanchang China) First Affiliated Hospital. The PCP specimens were obtained from patients who had been pathologically and clinically diagnosed with PCPs. The tumours were either kept at $-80^{\circ} \mathrm{C}$ until DNA/protein extraction or collected immediately for primary culture after resection. Healthy brain tissue samples were obtained from patients with conditions other than $\mathrm{CP}$, such as acute brain trauma or epilepsy [10]. Written informed consent was obtained from all the study participants before the clinical samples were used for research purposes. Ethical clearance was approved by the Research Ethical Committee of the Nanchang University.

\section{Primary cell culture}

Fresh PCP tissues were obtained from solid tumor specimens immediately after surgical removal. The tissues were washed with phosphate-buffered saline (PBS) containing 1\% penicillin/streptomycin (Life Technologies, Gibco BRL, Grand Island, USA), and then dissected into pieces of 2 to $3 \mathrm{~mm}$ in size. The 
tissues were then digested with $0.25 \%$ trypsin (Sigma-Aldrich, St. Louis, MO, USA) and $1 \mathrm{mg} / \mathrm{mL}$ collagenase II (Sigma-Aldrich, St. Louis, MO, USA) for 30 minutes at $37^{\circ} \mathrm{C}$ in a shaker incubator. After centrifugation at $1000 \times \mathrm{g}$ at $4^{\circ} \mathrm{C}$ for 10 minutes, the supernatant was discarded, and the pellet was resuspended in Dulbecco's modified Eagle's medium (high glucose, DMEM-HG), containing $10 \%$ fetal bovine serum (Life Technologies). The suspended primary PCP cells were cultured in defined serum-free keratinocyte medium (Invitrogen, Carlsbad, CA, USA). The cells were cultured in a constant-temperature incubator maintained at $37^{\circ} \mathrm{C}$, and $5 \% \mathrm{CO}$. Cell purification was carried out to define a well-formed primary PCP cell line.

\section{Cell counting kit-8 assay}

$4 \times 103$ cells in suspension were seeded in a 96-well plate. Different concentrations of the LY294002 were used to treat the cells for $4 \mathrm{~h}$, in triplicates. $10 \mu \mathrm{l} \mathrm{CCK}-8$ reagent was added to the wells and kept for $4 \mathrm{~h}$ to form formazan. Finally, the plate was examined at $450-490 \mathrm{~nm}$ on a microplate reader. Six replicate wells were set up in each group.

\section{Colony formation assay}

A total of $5 \times 102$ cells/well were seeded in 6-well plates until most of them adhered to the bottom and then different concentrations of LY294002 were added. After two weeks, the cells were fixed, stained and then colonies containing $\geq 20$ cells were counted.

\section{Wound healing assay}

A total of $5 \times 104$ cells were seeded in each well in a 6 -well plate for 24 hours. A cell layer was scratched by a pipette tip $(200 \mu \mathrm{L})$. The cells were then sub-cultured with the indicated concentrations of LY294002. Representative wounds were imaged by an optical microscope. Each of the experiments was conducted three times.

\section{Cell invasion and migration assay}

The Transwell assay was employed to assess the migratory and invasive abilities of the cells. The cells were seeded into 24-well Transwell Boyden chambers ( $8.0 \mu \mathrm{m}$ pore size; Costar, Cambridge, MA) following the manufacturer's instructions. Briefly, for the Transwell cell migration assay, $5 \times 104$ cells were suspended in $200 \mu \mathrm{l}$ DMEM media without FBS, and then added to the upper chambers. $700 \mu \mathrm{l}$ DMEM containing $30 \%$ FBS was added into the lower chambers and incubated for $24 \mathrm{~h}$ at $37^{\circ} \mathrm{C}$. For the Transwell cell invasion assay, $5 \times 104$ cells were suspended in $200 \mu$ DMEM without FBS and added to the upper chambers, which had been filled with $100 \mu \mathrm{l}$ Matrigel, then $700 \mu \mathrm{l}$ DMEM containing 30\% FBS was added into the lower chambers and incubated for $48 \mathrm{~h}$ at $37^{\circ} \mathrm{C}$. Thereafter, non-invasive cells on the inner surfaces of the upper chambers were gently scraped off using a cotton swab. On the other hand, invasive cells were fixed with $100 \%$ methanol, stained with $0.5 \%$ crystal violet solution, and washed with $1 \times$ PBS. The cells were then counted and photographed using a microscope $(\times 100)$. The experiments were independently repeated for at least three times. 


\section{Evaluation of apoptosis}

Apoptotic cell death was measured using AnnexinV-APC/7-AAD, following the manufacturer's protocols. Briefly, PCP cancer cells were seeded at a density of $5 \times 10^{4}$ cells per well in a 6-well plate, and then cultured for $24 \mathrm{~h}$ in DMEM medium. Samples were subsequently treated with various concentrations of $\operatorname{LY} 294002(0,10,20,30,60$ or $90 \mu \mathrm{M})$ for $24 \mathrm{~h}$, after which the cells were digested with $0.25 \%$ pancreatin and washed twice with $0.001 \%$ FBS-PBS buffer. $10 \mu \mathrm{L}$ of the cell suspension was added to microcentrifuge tubes containing $100 \mu \mathrm{L}$ of reagent and incubated for $10 \mathrm{~min}$ at room temperature. The cells were then analyzed using a BriCyte E6. Flow cytometry data was obtained from 5000 events (gated cells) per sample and the percentages of cells were estimated from the mean fluorescence intensity in each of the four quadrants. The coefficient of variation from the mean fluorescence was less than $10 \%$.

\section{Cell cycle analysis}

Cell cycle assays was measured using the cell cycle analysis kit (KGA512), following the manufacturer's protocol. Briefly, the PCP cancer cells were seeded at a density of $5 \times 104$ cells per well in a 6 -well plate, and then cultured for $24 \mathrm{~h}$ in DMEM medium. Samples were subsequently treated with various concentrations of LY294002 $(0,10,20,30,60$ and $90 \mu \mathrm{M})$ for $24 \mathrm{~h}$. The cells were then digested with $0.25 \%$ pancreatin and washed twice with $0.001 \%$ FBS-PBS buffer. The cells were resuspend in $100 \mathrm{ul}$ PBS and slowly added 700 ul pre-chilled $80 \%$ ethanol to make the final ethanol concentration $70 \%$, at $4{ }^{\circ} \mathrm{C}$. They were fixed for $4 \mathrm{~h}$, span at $1000 \mathrm{rpm}$ for $5 \mathrm{~min}$ and then rinsed twice in pre-chilled PBS. 100ul RNase (50ug / ml) was added and left at $37^{\circ} \mathrm{C}$ water bath for $30 \mathrm{~min}$. We then added $400 \mathrm{ul} \mathrm{PI} \mathrm{(50ug} \mathrm{/} \mathrm{ml}$ ) and stained at $4^{\circ} \mathrm{C}$ for $30 \mathrm{~min}$ in the dark. The cells were analyzed using a BriCyte E6.

\section{Immunofluorescence assay}

Primary PCP cells were washed with PBS and then fixed in 75\% ethanol for 20 minutes at room temperature. The cells were blocked with $5 \%$ bovine serum albumin (BSA) for $1 \mathrm{~h}$ at $37^{\circ} \mathrm{C}$, and then incubated with monoclonal anti-human pan-cytokeratin (pan-CK, Abcam, ab215838, 1:100, Cambridge, UK), anti-vimentin (VIM, CST, 5742T, 1:100), anti- p-PI3K (p85) (Abcam, ab182651, 1:200), anti-PI3K (Abcam, ab191606, 1:200), anti-p-AKT (S473) (Abcam, ab8932, 1:200), or anti-AKT (Abcam, ab8805, 1:200) at $4^{\circ} \mathrm{C}$, overnight. The cells were washed with PBS and then incubated with secondary antibody; Alexa 488-conjugated goat anti-mouse or anti-rabbit IgG (Abcam). After the application of counterstain nuclei,4',6-diamidino-2-phenylindole (DAPI, $10 \mu \mathrm{g} / \mathrm{mL}, 32670$; Sigma-Aldrich), fluorescent images were obtained using a microscope (Carl Zeiss, Germany) and processed using Photoshop software (Adobe).

\section{Western blotting (WB)}

Total proteins were extracted from the cultured cells after treatment with or without LY294002 after preparation of the PCP tissues with RIPA lysis buffer (Beyotime Institute of Biotechnology, Jiangsu, china). The proteins were quantified using a Pierce BCA protein Assay kit (Thermo Fisher Scientific, Inc.). Cell or tissue lysates of 30 ug protein samples were then resolved in a 10-15\% SDS-PAGE gels and 
transferred to PVDF membranes (Millipore, Billerica, MA, USA). The membranes were then stained with $0.5 \%$ Ponceau $S$ with $1 \%$ acetic acid to ensure equal loading. After blocking with $5 \%$ BSA in PBS and Tween-20 (PBS-T) for $1 \mathrm{~h}$, the PVDF membranes were incubated overnight with primary antibodies: monoclonal antibodies against GAPDH (Abcam, ab8245, 1:1000), p-PI3K (p85) (Abcam, ab182651, 1:5000), PI3K (Abcam, ab191606, 1:5000), p-AKT (S473) (Abcam, ab8932, 1:2000), or AKT (Abcam, ab8805, 1:2000). The membranes were then washed three times in Tris-buffered saline and Tween-20 (TBST) for 10 minutes, and then incubated with the secondary antibody; horseradish peroxidase (HRP)labeled goat anti-rabbit (CST, 7074, 1:4000) or anti-mouse (CST, 7076, 1:4000) for $1 \mathrm{~h}$ at room temperature (RT). Protein bands were visualized by enhanced chemiluminescence (ECL).

\section{Statistical analysis}

All data were presented as a mean \pm SEM for at least three independent experiments. A one-way analysis of variance and Duncan multiple-comparison test in SPSS 19.0 (SPSS Inc., Chicago, IL) we employed to calculate the statistical significance. $P<0.05, P<0.01$, or $P<0.001$ was considered statistically significant.

\section{Results}

\section{p-PI3K, p-AKT expression level in PCP cancer tissues.}

To study whether the PI3K/AKT signaling pathway is clinically relevant in PCP cancer, the expression levels of p-PI3K and total PI3K, or p-AKT and total AKT were determined in human PCP tissue by Western blot (WB)[10]. Compared with the normal brain tissues, there was higher expression of $\mathrm{p}-\mathrm{PI} 3 \mathrm{~K} /$ total PI3K and $p-A K T /$ total AKT in the PCP tissues $(P<0.001)$ (Figure 1). Moreover, treatment with LY294002 decreased the expression of p-PI3K or p-Akt proteins in PCP cells, compared with the untreated (Figure 3). This data demonstrates the ability of the LY294002 to suppress the activation of the PI3K/Akt signaling pathway.

\section{Cultivation of primary PCP tumor cells.}

To further determine the biological roles of PI3K/AKT in PCP cells, we successfully isolated and cultured primary PCP cells from the patients. The cells were cultured for 7 days, and cell morphology was directly observed by inverted contrast microscope. Results showed that the primary cells had prominent spindlelike, round, or triangle cell bodies. We used pan-CK and vimentin (VIM) as the positive and negative controls in the detection of primary PCP cells by immunofluorescence assays [11, 12], Our data showed the expression of pan-CK in the cytoplasm of the PCP cells, while VIM was not detected (Figure2). These results indicated that the primary PCP cells were successfully cultured and were not contaminated by craniopharyngia-associated fibroblasts.

Effects of the PI3K inhibitor LY294002 on the regulation of PCP cell proliferation. 
The inhibitory effect of LY294002 on the viability of PCP cell lines was examined using the CCK assay. The results revealed that the PCP cell lines were sensitive to LY294002, thus LY294002 inhibited PCP cell viability in a time and dose-dependent manner (Figure $4 \mathrm{~A}$ ). IC50 value at $24 \mathrm{~h}$ was $22.28 \mu \mathrm{M}$.

To further define whether PI3K/AKT pathway was associated with PCP cell proliferation, log phase PCP cells were treated with doses of $10,20,30,60$ or $90 \mu \mathrm{M}$ of LY294002, and then cellular growth was measured. The growth curve data showed that LY294002 inhibited tumor cell growth (Figure 4A). Besides, a plate clone formation assay also showed a markedly decreased clone number following LY294002 treatment (Figure 4B, C).

\section{LY294002 induced cell cycle arrest and apoptosis in PCP cells}

Log phase PCP cells were treated with $\operatorname{LY} 294002(10,20,30 \rrbracket 60$ or $90 \mu \mathrm{M})$ and the cell cycle progression was determined using flow cytometry. The data showed that, after $24 \mathrm{~h}$ incubation time, LY294002 induced cell cycle arrest in PCP cells at the G1 / M phase in a dose dependent manner (Figure 5B, D). To assess the apoptotic cells, we stained the LY294002-exposed PCP cells with Annexin V bound to FITC, and analyzed by flow cytometry. Unlike the untreated cells, the flow cytometry data confirmed apoptosis in PCP cells treated with LY294002 (Figure 5A, C). Our data robustly revealed that LY294002-treatment induced apoptosis in PCP cells.

\section{Effects of the PI3K inhibitor LY294002 on regulation of PCP cell migration and invasion.}

The data from the Transwell tumor cell migration and invasion assays indicated a compromised migration and invasive ability of the PCPs cells following addition of LY294002 (Figure 6B, C). On the other hand, the scratch wound assay showed that the untreated control cells had a normal migratory behavior, with decreased open wound area, while the motility of LY294002-treated PCP cells was inhibited (Figure 6A).

\section{Discussion}

Craniopharyngioma represents one of the most difficult treatment paradigms in neurological tumors. Previous studies showed that mutations in CTNNB1 (encoding $\beta$-catenin), that lead to the overactivation of the WNT pathway, underlie the molecular etiology of human ACP [13].The molecular pathogenesis of PCP was largely undefined until exome sequencing studies identified BRAF mutations in $95 \%(51 / 53)$ of these tumors, but not in the ACP variants[15]. It is well established that the gain-of-function mutation BRAF-V600E, a critical serine/threonine kinase in the RasRaf-MekERK1/2 pathway, renders it a potent oncogene leading to increased cell proliferation and survival, resulting in cell transformation and tumorigenesis[16, 17].Over-expression of PI3K induced cell transformation in a MAPK/Erk- and Akt/mTOR-dependent manner [18].Previous studies have noted the importance of PI3K signaling in tumors. They demonstrated aberrant activation of the PI3K/AKT pathway in a number of tumor tissues, including craniopharyngioma, and inhibitors of the PI3K/AKT pathway have been investigated as potential anticancer therapies[19]. Here, there was upregulation of $p-P I 3 K, p-$ 
AKT in CP tumor tissues, in comparison with the normal brain tissue $(P<0.001)$ (Figure 1). Therefore, $\mathrm{PI} 3 \mathrm{~K} / \mathrm{AKT}$ play an important role in craniopharyngioma.

A number of studies have shown that PI3K/Akt inhibition may delay tumor growth, including renal cancer[20],breast cancer[21],glioblastoma[22], and neuroblastoma[23].In our study, the CCK-8 and plate colony formation assays demonstrated that LY294002 had a marked effect on PCP cell proliferation. Compared with the control group, LY294002 treatment significantly inhibited the proliferation of PCP cells. We postulated that LY294002 inhibits the cell cycle progression by inducing specific G1 arrest. As demonstrated previously in human melanoma cells, LY294002 inhibits cell proliferation by inhibiting G1 cyclin-dependent kinase activity and the subsequent phosphorylation of retinoblastoma protein [24].In addition, LY294002 has been suggested to increase apoptosis of PCPs[24]. Ras was found to protect cells from apoptosis through activation of Akt via PI3-K[25].LY294002, via the inhibition of PI3-K activity, blocks the signal transduction pathway, which in turn may inhibit Ras-mediated protection from apoptosis in PCP cancer. Studies have shown that LY294002 significantly inhibits the proliferation and enhanced apoptosis of PCP cells.

Treatment of PCPs cells, in vitro, with the higher $(30 \mu \mathrm{m})$ dose of LY294002 for $24 \mathrm{~h}$, was rendered toxic. There is decreased cellularity, and shrunken cell clusters, with poor cellular cohesion. However, there was partial recovery $24 \mathrm{~h}$ after withdrawal of $30 \mu \mathrm{m}$ LY294002. Whereas there was persistent decline in cellularity, the cells regained cohesion, and their nuclei and cytoplasm more closely resembled the appearance of the untreated cells. These observations both imply that the side effects associated with the LY294002 treatment in PCP cells are largely dependent on the dose and the time course of the LY294002 treatment, both of which might be reduced to avoid these side effects.

Taken together, our data demonstrate that LY294002 robustly inhibits cancer cell proliferation in vitro. Thus, PI3K plays an important role in the growth of the PCP cells and presents an attractive therapeutic target for the development of a novel treatment approach to PCPs.

\section{References}

\section{References:}

[1]. Goschzik, T., et al., Genomic Alterations of Adamantinomatous and Papillary Craniopharyngioma. J Neuropathol Exp Neurol, 2017. 76(2): p. 126-134.

[2]. Preda, V., et al., The Wnt signalling cascade and the adherens junction complex in craniopharyngioma tumorigenesis. Endocr Pathol, 2015. 26(1): p. 1-8.

[3]. Hölsken, A., et al., Adamantinomatous and papillary craniopharyngiomas are characterized by distinct epigenomic as well as mutational and transcriptomic profiles. Acta Neuropathol Commun, 2016. 4: p. 20. 
[4]. Brastianos, P.K., et al., Exome sequencing identifies BRAF mutations in papillary craniopharyngiomas. Nat Genet, 2014. 46(2): p. 161-5.

[5]. Brown, H.A., P.G. Thomas and C.W. Lindsley, Targeting phospholipase D in cancer, infection and neurodegenerative disorders. Nat Rev Drug Discov, 2017. 16(5): p. 351-367.

[6]. Martini, M., et al., PI3K/AKT signaling pathway and cancer: an updated review. Ann Med, 2014. 46(6): p. $372-83$.

[7]. Alzahrani, A.S., PI3K/Akt/mTOR inhibitors in cancer: At the bench and bedside. Semin Cancer Biol, 2019. 59: p. 125-132.

[8]. Gehringer, F., et al., Physiological levels of the PTEN-PI3K-AKT axis activity are required for maintenance of Burkitt lymphoma. Leukemia, 2020. 34(3): p. 857-871.

[9]. Ho, C.J. and S.M. Gorski, Molecular Mechanisms Underlying Autophagy-Mediated Treatment Resistance in Cancer. Cancers (Basel), 2019. 11(11).

[10]. Wang, Y., et al., Clinical and prognostic role of annexin A2 in adamantinomatous craniopharyngioma. J Neurooncol, 2017. 131(1): p. 21-29.

[11]. Nelson, W.G., et al., Specific keratins as molecular markers for neoplasms with a stratified epithelial origin. Cancer Res, 1984. 44(4): p. 1600-3.

[12]. Quentmeier, H., et al., Immunocytochemical analysis of cell lines derived from solid tumors. J Histochem Cytochem, 2001. 49(11): p. 1369-78.

[13]. Zhang, N., [Vimentin and tumor diagnosis]. Zhonghua Bing Li Xue Za Zhi, 1990. 19(2): p. 122-4.

[14]. Martinez-Barbera, J.P. and R. Buslei, Adamantinomatous craniopharyngioma: pathology, molecular genetics and mouse models. J Pediatr Endocrinol Metab, 2015. 28(1-2): p. 7-17.

[15]. Amit, S., et al., Axin-mediated CKI phosphorylation of beta-catenin at Ser 45: a molecular switch for the Wnt pathway. Genes Dev, 2002. 16(9): p. 1066-76.

[16]. Davies, H., et al., Mutations of the BRAF gene in human cancer. Nature, 2002. 417(6892): p. 94954.

[17]. Haston, S., et al., MAPK pathway control of stem cell proliferation and differentiation in the embryonic pituitary provides insights into the pathogenesis of papillary craniopharyngioma. Development, 2017. 144(12): p. 2141-2152.

[18]. Davis, W.J., P.Z. Lehmann and W. Li, Nuclear PI3K signaling in cell growth and tumorigenesis. Front Cell Dev Biol, 2015. 3: p. 24. 
[19]. Shingu, T., et al., Synergistic augmentation of antimicrotubule agent-induced cytotoxicity by a phosphoinositide 3-kinase inhibitor in human malignant glioma cells. Cancer Res, 2003. 63(14): p. 40447.

[20]. Sourbier, C., et al., The phosphoinositide 3-kinase/Akt pathway: a new target in human renal cell carcinoma therapy. Cancer Res, 2006. 66(10): p. 5130-42.

[21]. Mallon, R., et al., Antitumor efficacy of PKI-587, a highly potent dual PI3K/mTOR kinase inhibitor. Clin Cancer Res, 2011. 17(10): p. 3193-203.

[22]. Zhao, H.F., et al., Recent advances in the use of PI3K inhibitors for glioblastoma multiforme: current preclinical and clinical development. Mol Cancer, 2017. 16(1): p. 100.

[23]. Mohlin, S., et al., Anti-tumor effects of PIM/PI3K/mTOR triple kinase inhibitor IBL-302 in neuroblastoma. EMBO Mol Med, 2019. 11(8): p. e10058.

[24]. Shayesteh, L., et al., PIK3CA is implicated as an oncogene in ovarian cancer. Nat Genet, 1999. 21(1): p. 99-102.

[25]. Downward, J., Ras signalling and apoptosis. Curr Opin Genet Dev, 1998. 8(1): p. 49-54.

\section{Declarations}

\section{Acknowledgements}

\section{Funding}

This work was supported by the National Natural Science Foundation of China (grant nos. 81560207 and 81460381), Ganpo555 engineering excellence of Jiangxi Science and Technology Department (2013), Key research and invention plan of Jiangxi Science and Technology Department (20192BBG70026), Natural Science Foundation of Jiangxi Province(2014ZBAB205019), Education Department of Jiangxi Province (GJJ13031)

\section{Availability of data and materials}

Data sharing is not applicable to this article, as no datasets were generated or analyzed during the current study.The data used to support the findings of this study were supplied by [Tao Hong] under license and so cannot be made freely available. Requests for access to these data should be made to [Tao Hong, ht2000@vip.sina.com].

\section{Authors' contributions}

LIN ZHOU and CHENXING OUYANG performed the experiments and generated data. LIN ZHOU, LINCHUN FANG SHIHAI LAN, XIAO WUQYOUYUAN BAO SUYUE ZHENG SHAOYANG LI and MINDE LI analyzed data. 
HONG TAO designed experiments. TAO HONG wrote the manuscript. All authors reviewed and approved the manuscript.

\section{Ethics approval and consent to participate}

The present study was approved by the Research Ethics Committee of the First Affiliated Hospital, Nanchang University (Nanchang, China).

\section{Patient consent for publication}

Not applicable.

\section{Competing interests}

The authors declare that they have no competing interests.

\section{Figures}

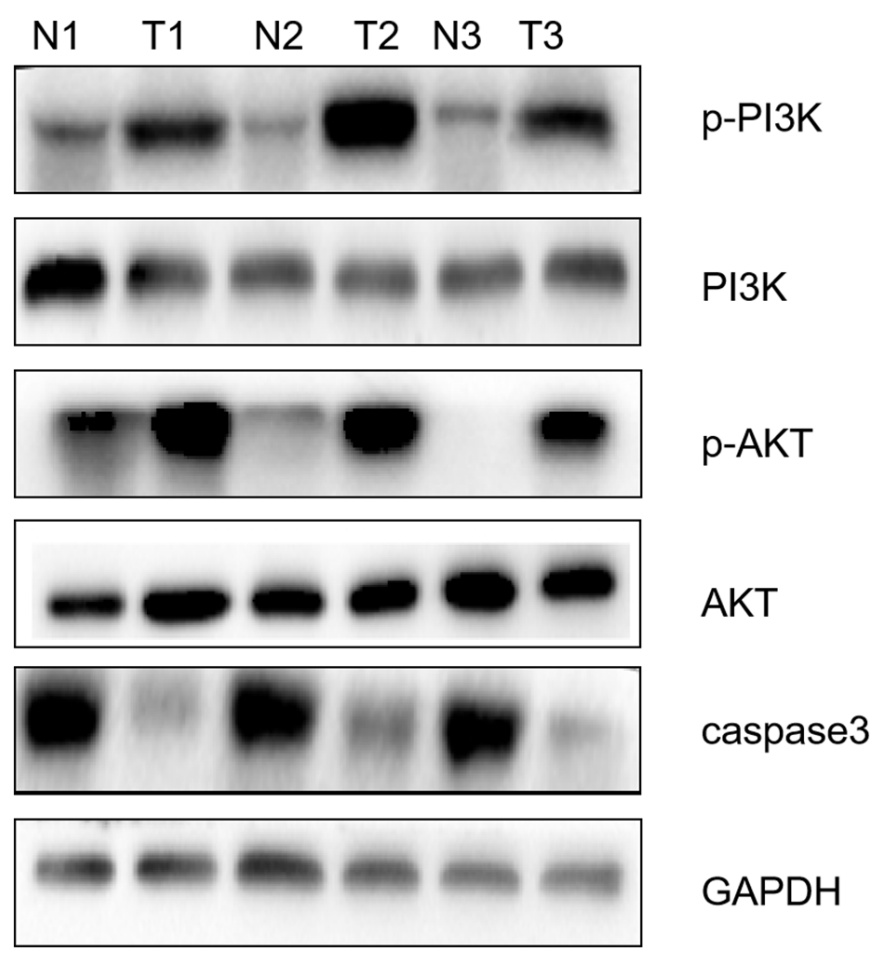

\section{Figure 1}

The relative expression quantities of p-PI3K $\square$ p-AKT in craniopharyngioma tissues compared with normal controls were detected by western blotting. 


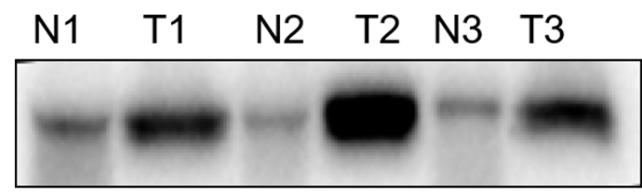

p-PI3K

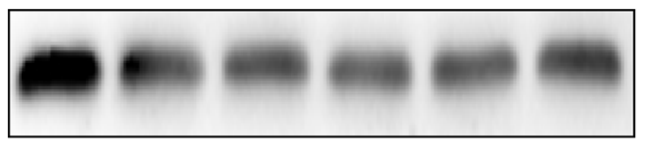

PI3K

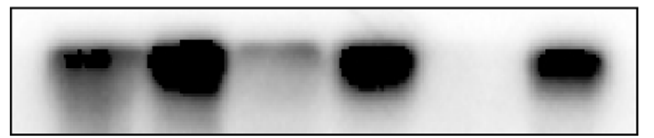

p-AKT

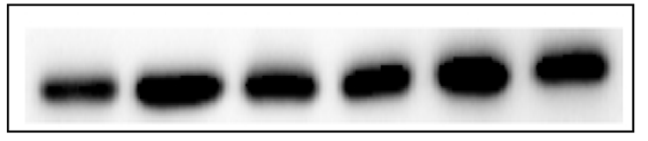

AKT

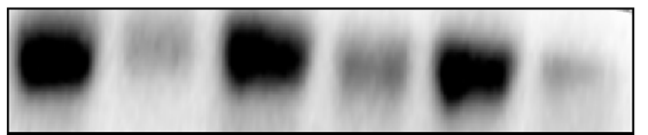

caspase3

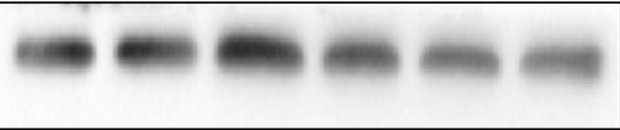

GAPDH

\section{Figure 1}

The relative expression quantities of p-PI3K $\square$ p-AKT in craniopharyngioma tissues compared with normal controls were detected by western blotting.

vimentin

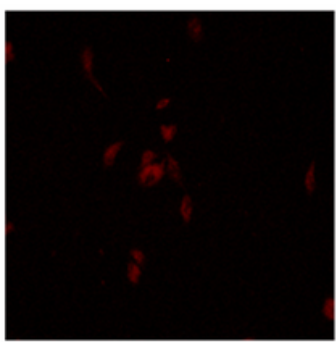

keratin

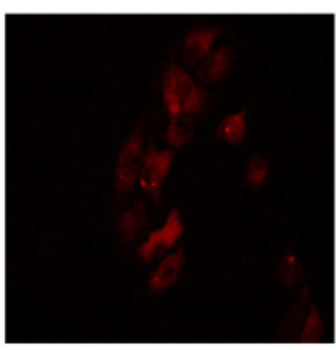

DAPI
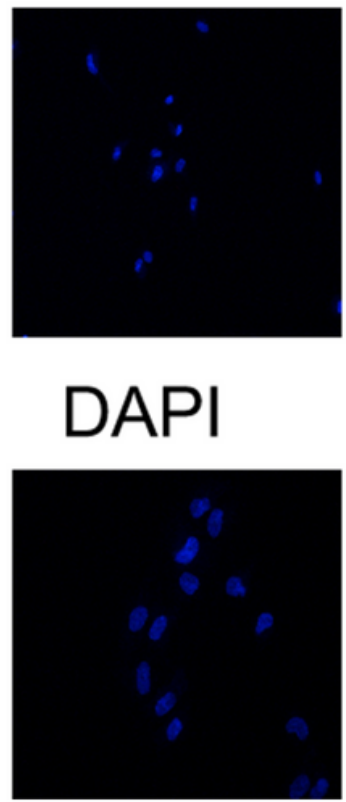

Merge

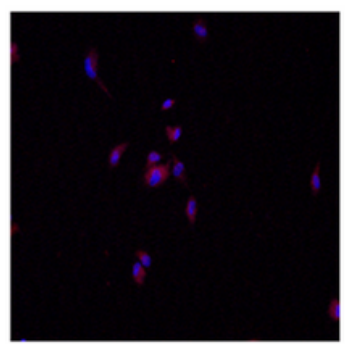

Merge

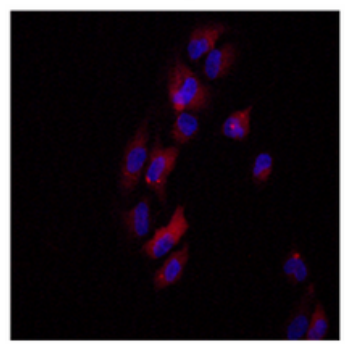


Figure 2

Validation of primary PCPs cells.Immunofluorescence of primary PCPs cell to detect pan-CK and VIM using DAPI to label DNA. PCPs, papillary craniopharyngioma; DAPI, 4',6-diamidino-2-phenylindole; panCK, pan cytokeratin; VIM, vimentin.

\section{vimentin DAPI Merge}
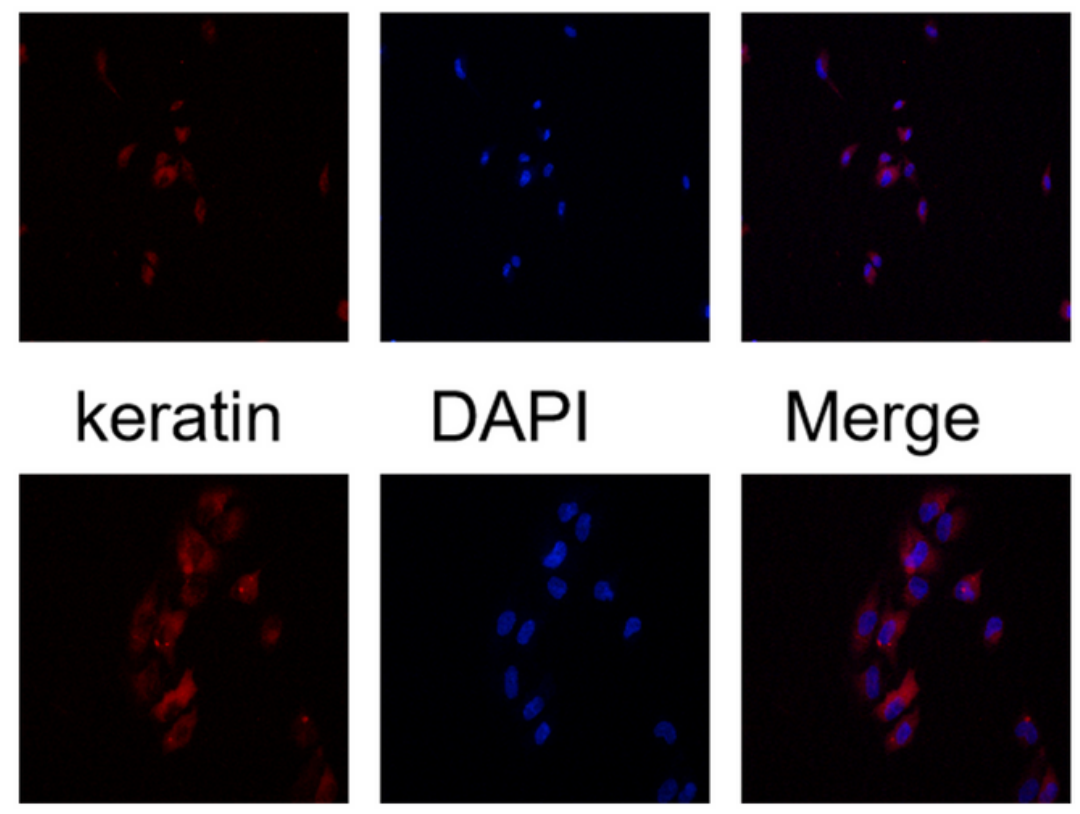

Figure 2

Validation of primary PCPs cells.Immunofluorescence of primary PCPs cell to detect pan-CK and VIM using DAPI to label DNA. PCPs, papillary craniopharyngioma; DAPI, 4',6-diamidino-2-phenylindole; panCK, pan cytokeratin; VIM, vimentin. 
A

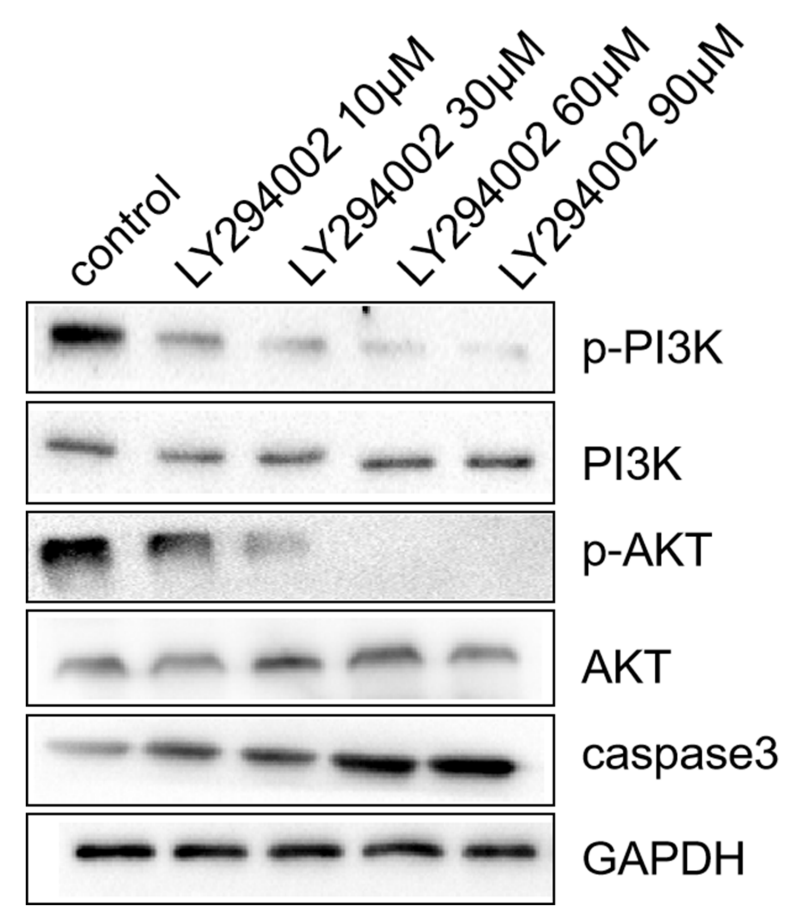

B
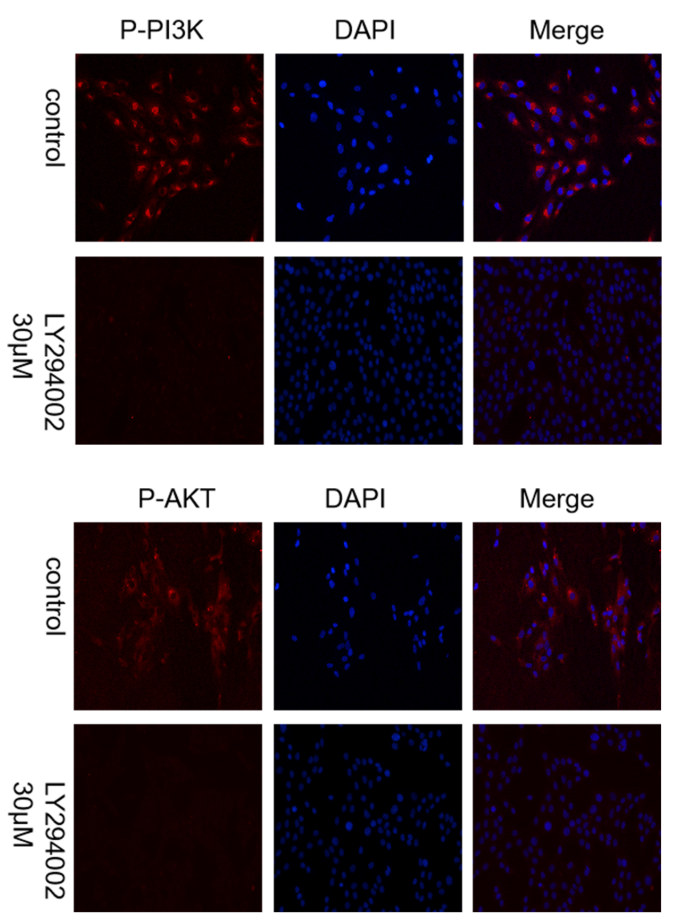

Figure 3

LY294002 influence p-PI3K $\square$ p-AKT expression in PCPs cells. Cells were treated with 30 $\mu$ m LY294002 for $24 \mathrm{~h}$,immounofluoence assay and WB was used to detect the expression of p-PI3K $\square p-A K T(A, B)$. 
A

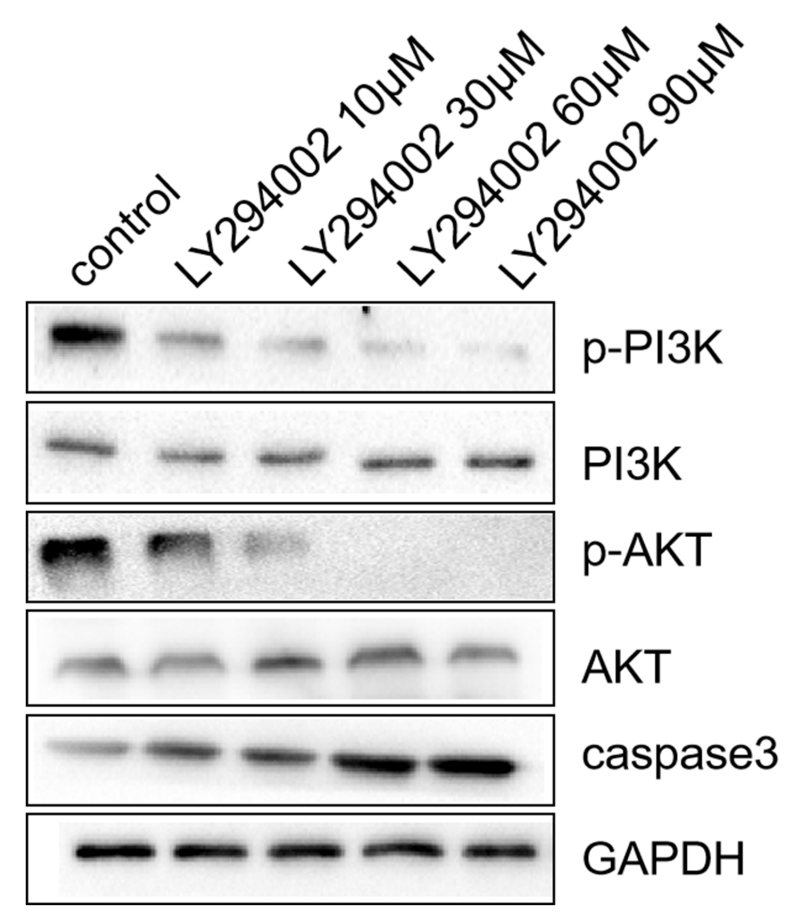

B
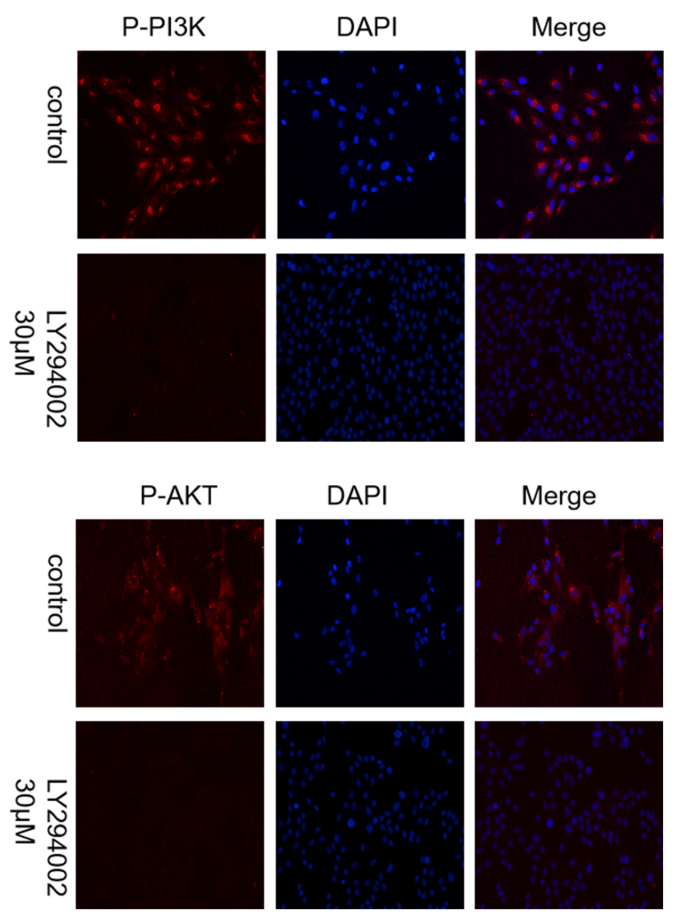

Figure 3

LY294002 influence p-PI3K $\square$ p-AKT expression in PCPs cells. Cells were treated with 30 $\mu$ m LY294002 for $24 \mathrm{~h}$,immounofluoence assay and WB was used to detect the expression of p-PI3K $\square p-A K T(A, B)$. 


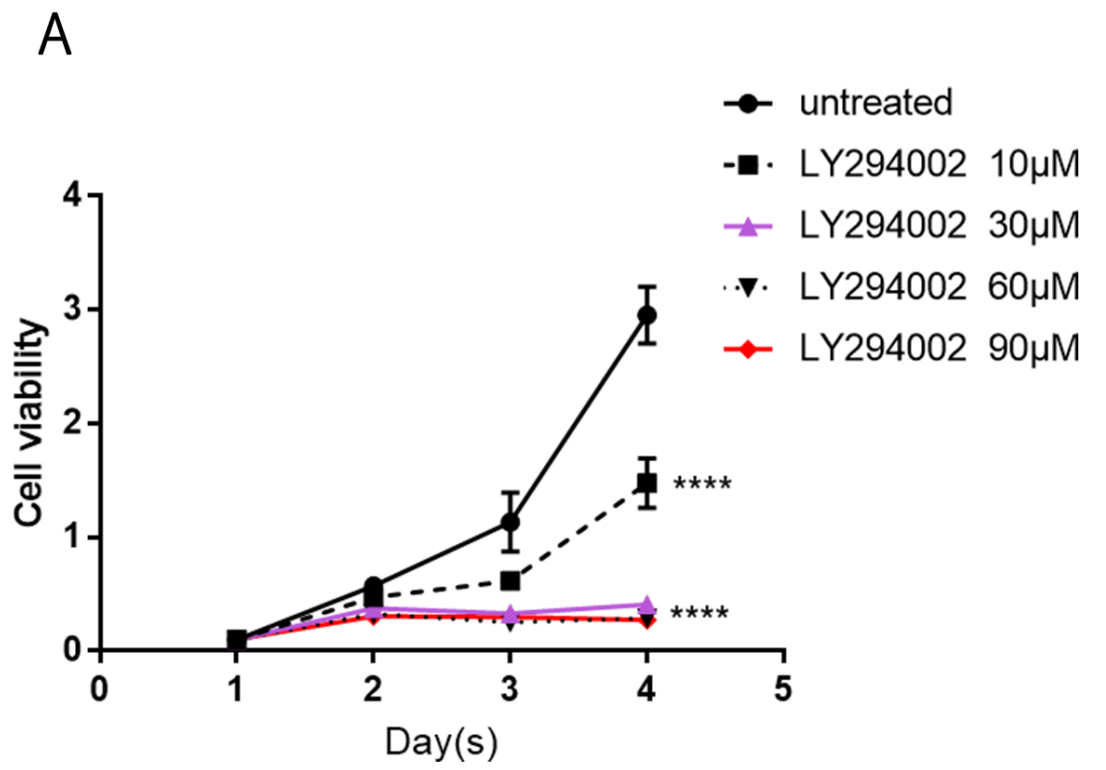

B

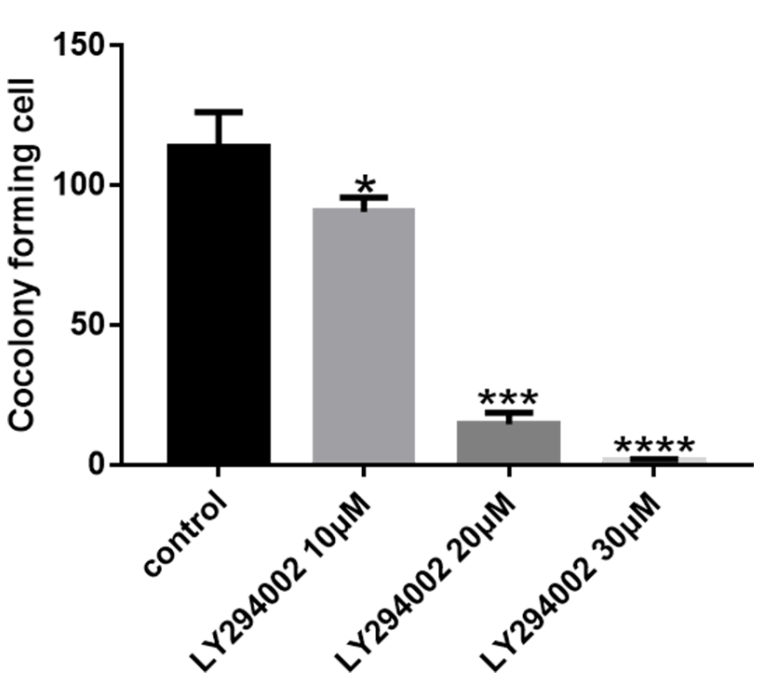

C control

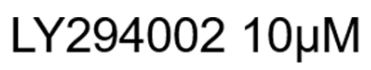

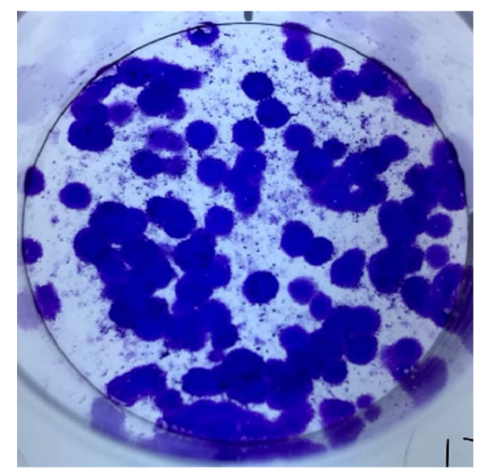

LY294002 20HM

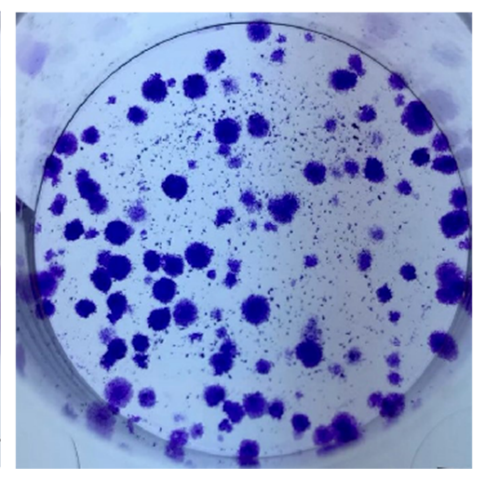

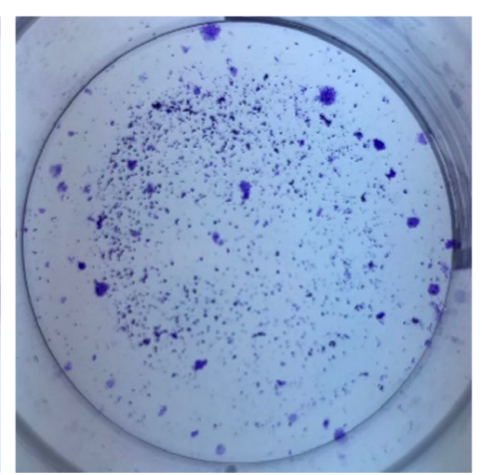

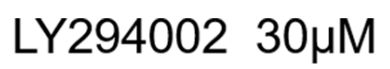

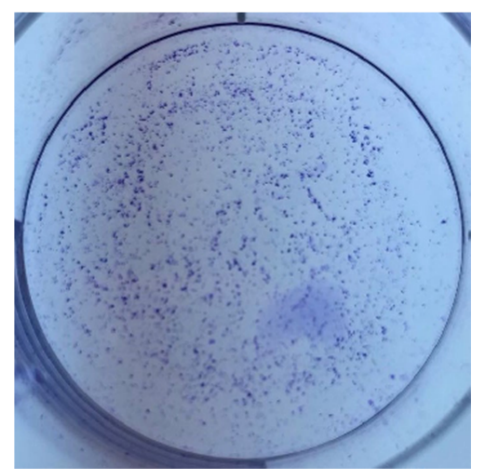

Figure 4

The influence of LY294002 on the proliferation of PCPs cells.CCK-8 ,colony formation assay detected that cell proliferation vitality $(A B) .(* \star \star p<0.001 ; * \star p<0.01 ; * p<0.05)$. 


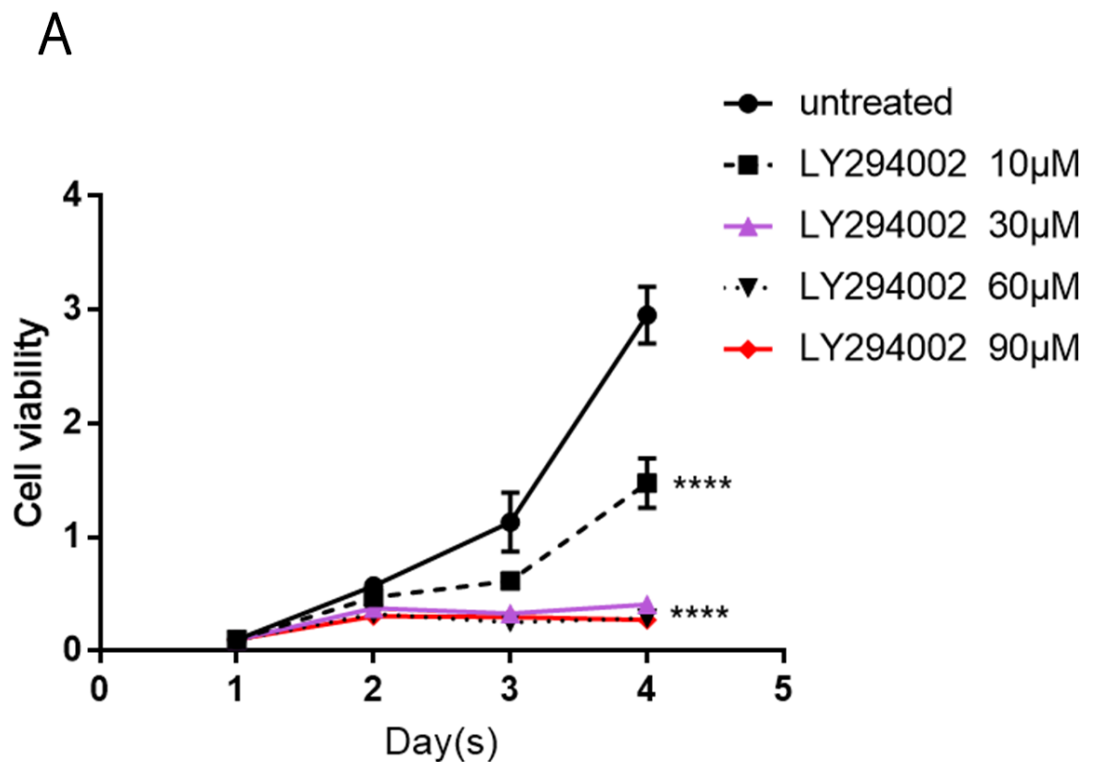

B

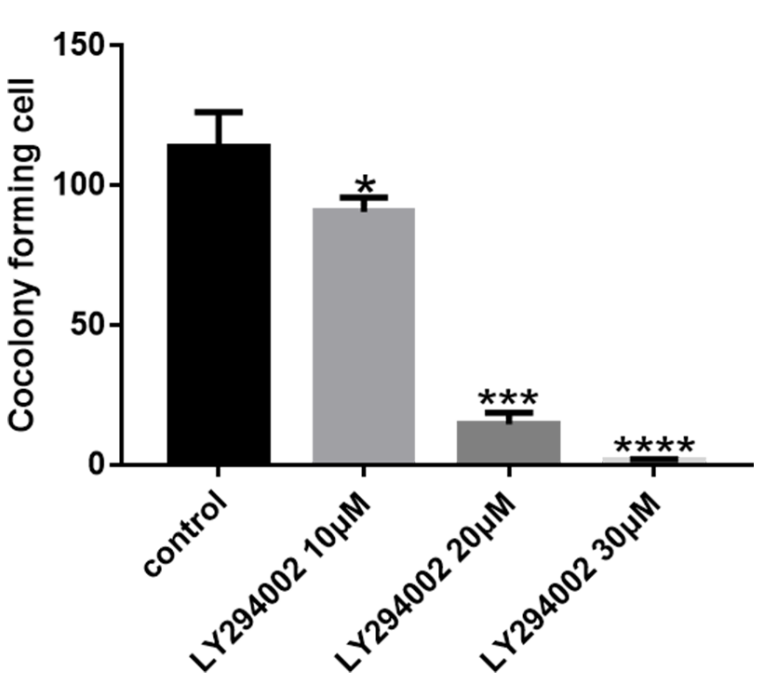

C control

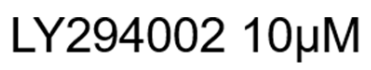

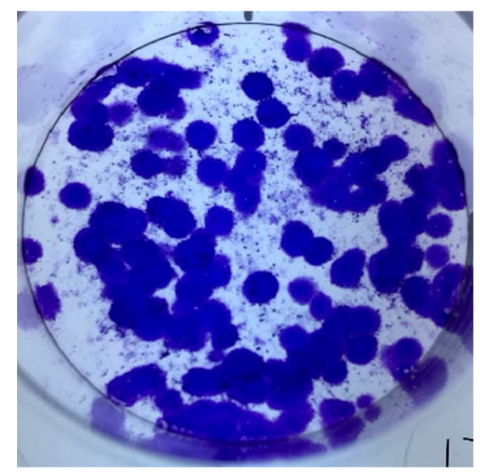

LY294002 20HM

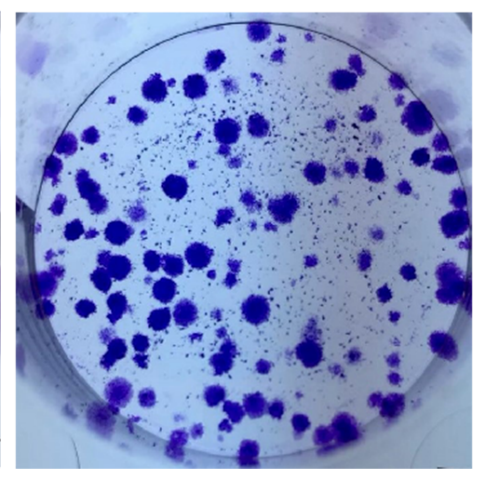

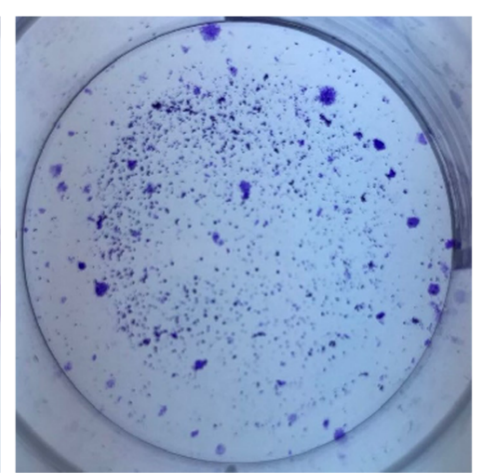

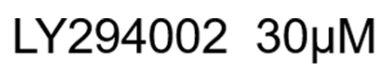

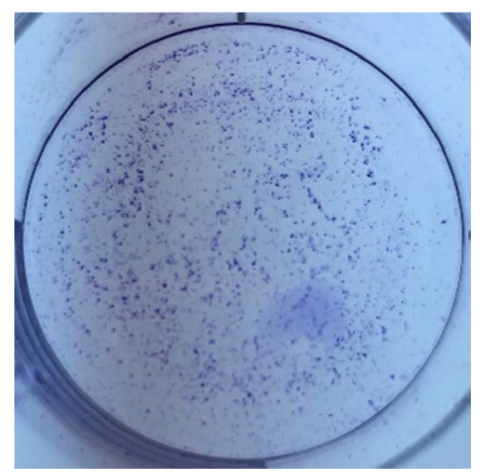

Figure 4

The influence of LY294002 on the proliferation of PCPs cells.CCK-8 ,colony formation assay detected that cell proliferation vitality $(A B) .(* \star \star p<0.001 ; * \star p<0.01 ; * p<0.05)$. 


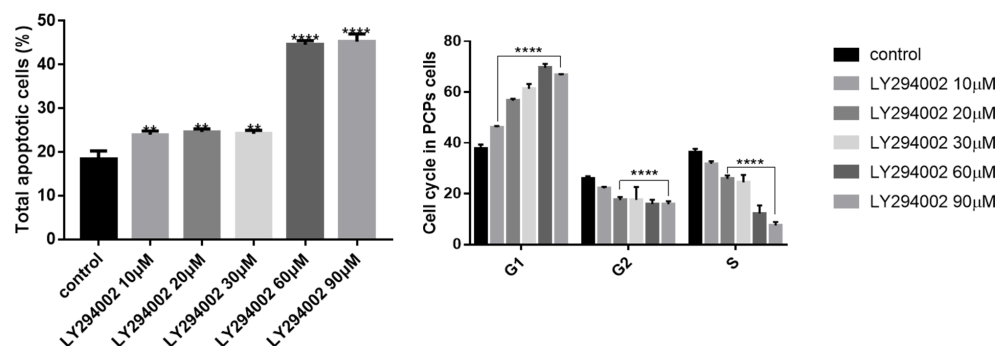

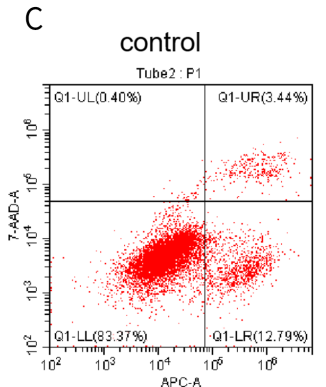

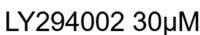

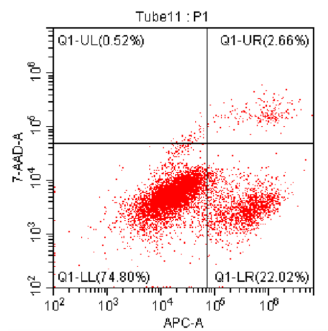

D

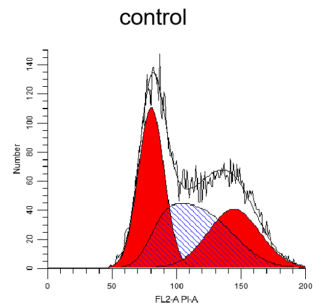

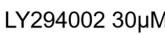

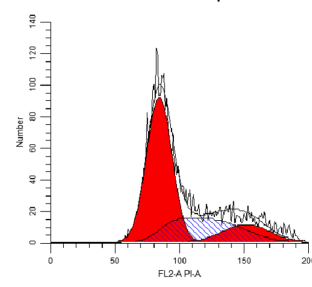

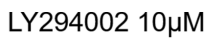

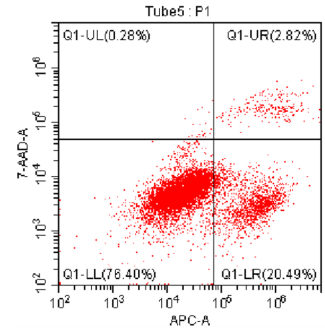

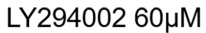

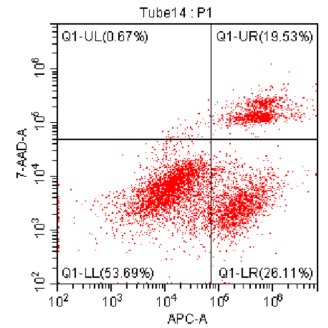

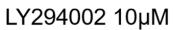

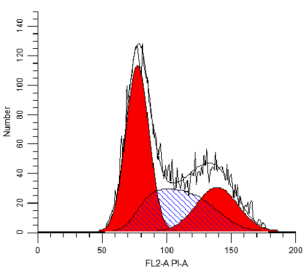

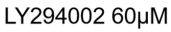

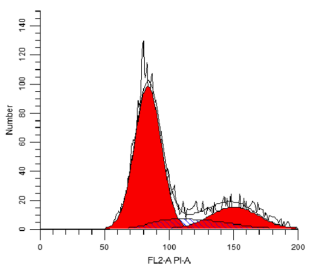

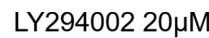

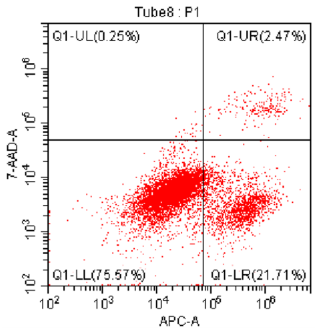

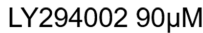

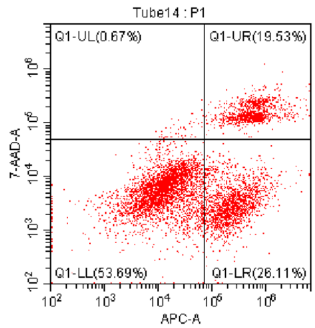

LY294002 20HM

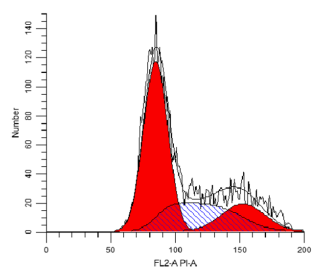

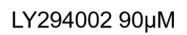

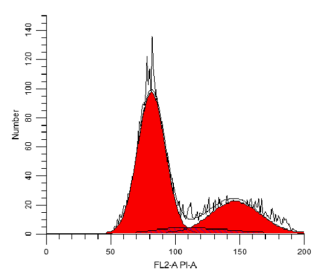

Figure 5

Effect of LY294002 on the apoptosis and cell cycle of PCPs cells. Cells were treated with or without 10, 20,30,60, and $90 \mu \mathrm{M}$ LY294002 for $24 \mathrm{~h}$. Apoptotic cell death was measured by Annexin V staining assay $(A, C)$.Cell cycle changes for PCPs cells(D), treated in increasing concentrations of the inhibitor displayed as bar graphs of different phases of the cell cycle (B) measured. 


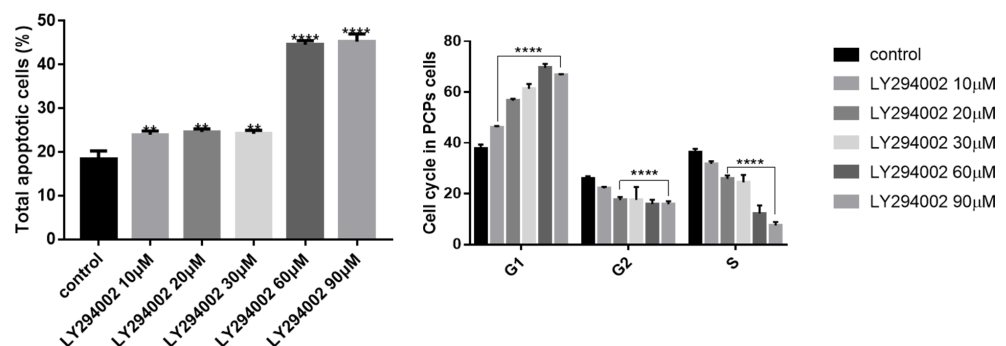

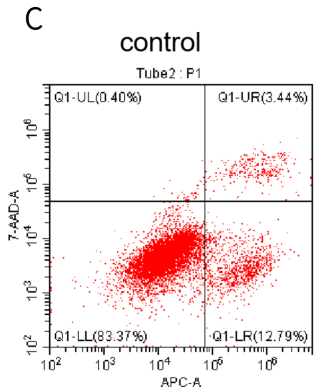

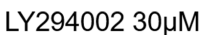

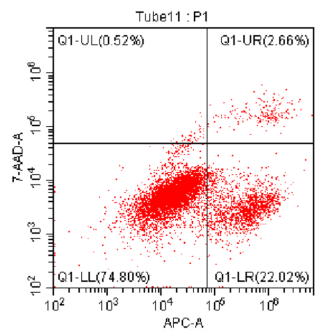

D

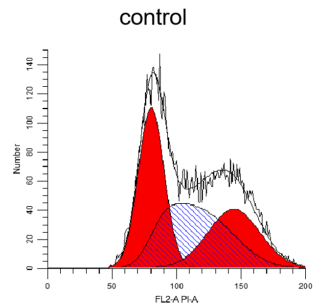

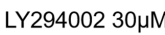

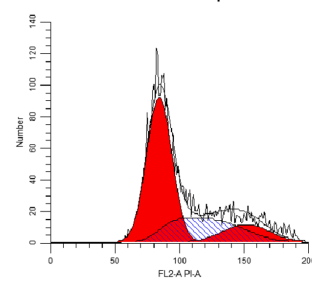

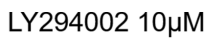

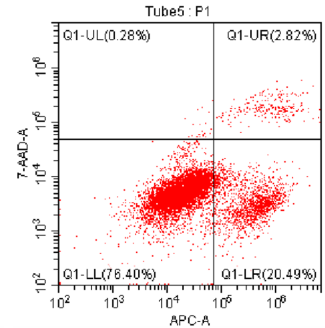

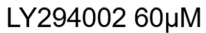

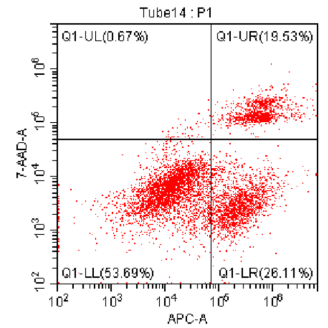

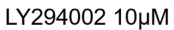

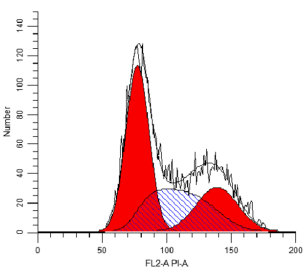

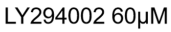

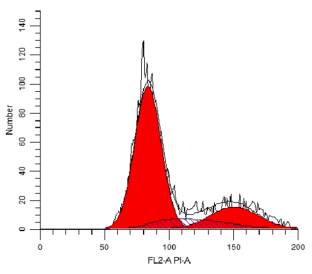

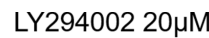

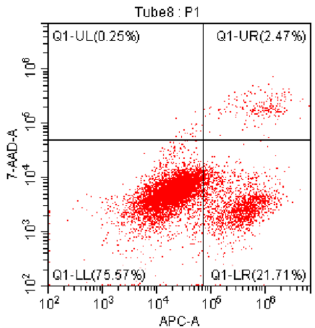

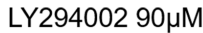

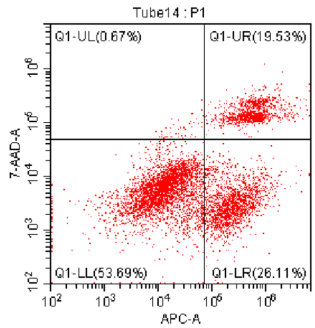

LY294002 20HM

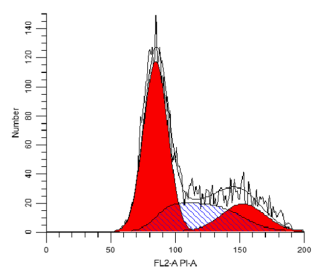

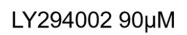

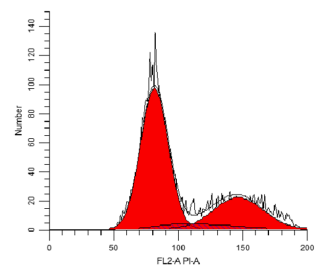

Figure 5

Effect of LY294002 on the apoptosis and cell cycle of PCPs cells. Cells were treated with or without 10, 20,30,60, and $90 \mu \mathrm{M}$ LY294002 for $24 \mathrm{~h}$. Apoptotic cell death was measured by Annexin V staining assay $(A, C)$.Cell cycle changes for PCPs cells(D), treated in increasing concentrations of the inhibitor displayed as bar graphs of different phases of the cell cycle (B) measured. 
A
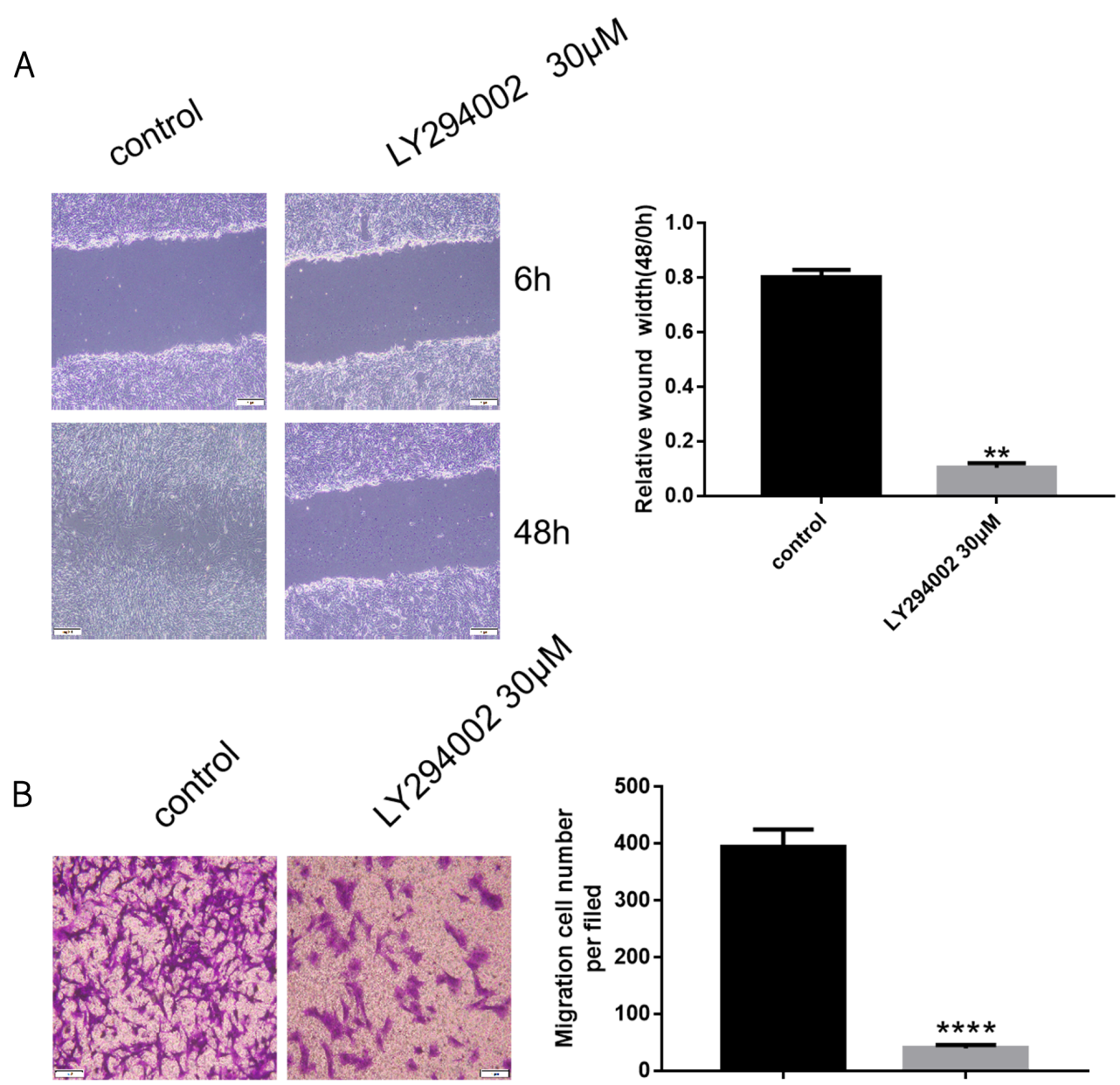

C
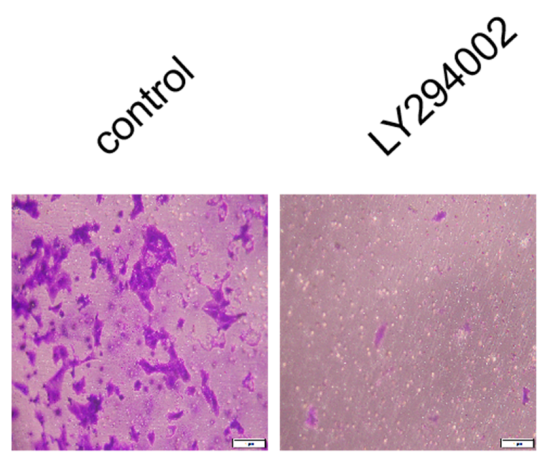<smiles>[CH]1C[CH]C1</smiles>
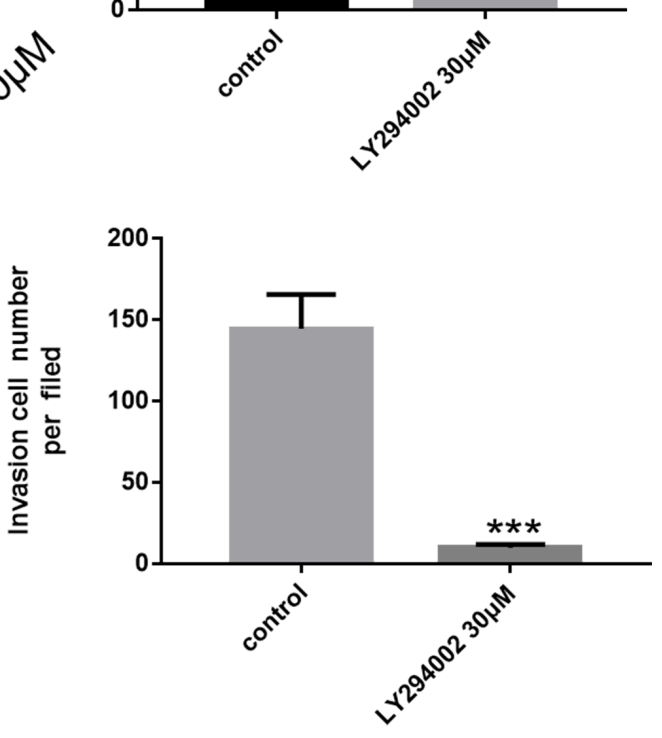

\section{Figure 6}

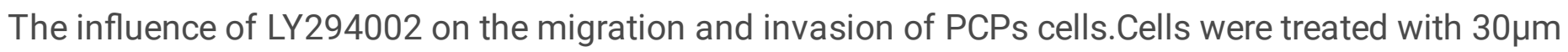
LY294002 for24 h,wound healing \transwell assay was used to detect the changes of PCPs cells migration and invasion capacity(magnification, $x 200),(A, B, C) .(* \star \star p<0.001 ; * \star p<0.01 ; * p<0.05)$. 
A
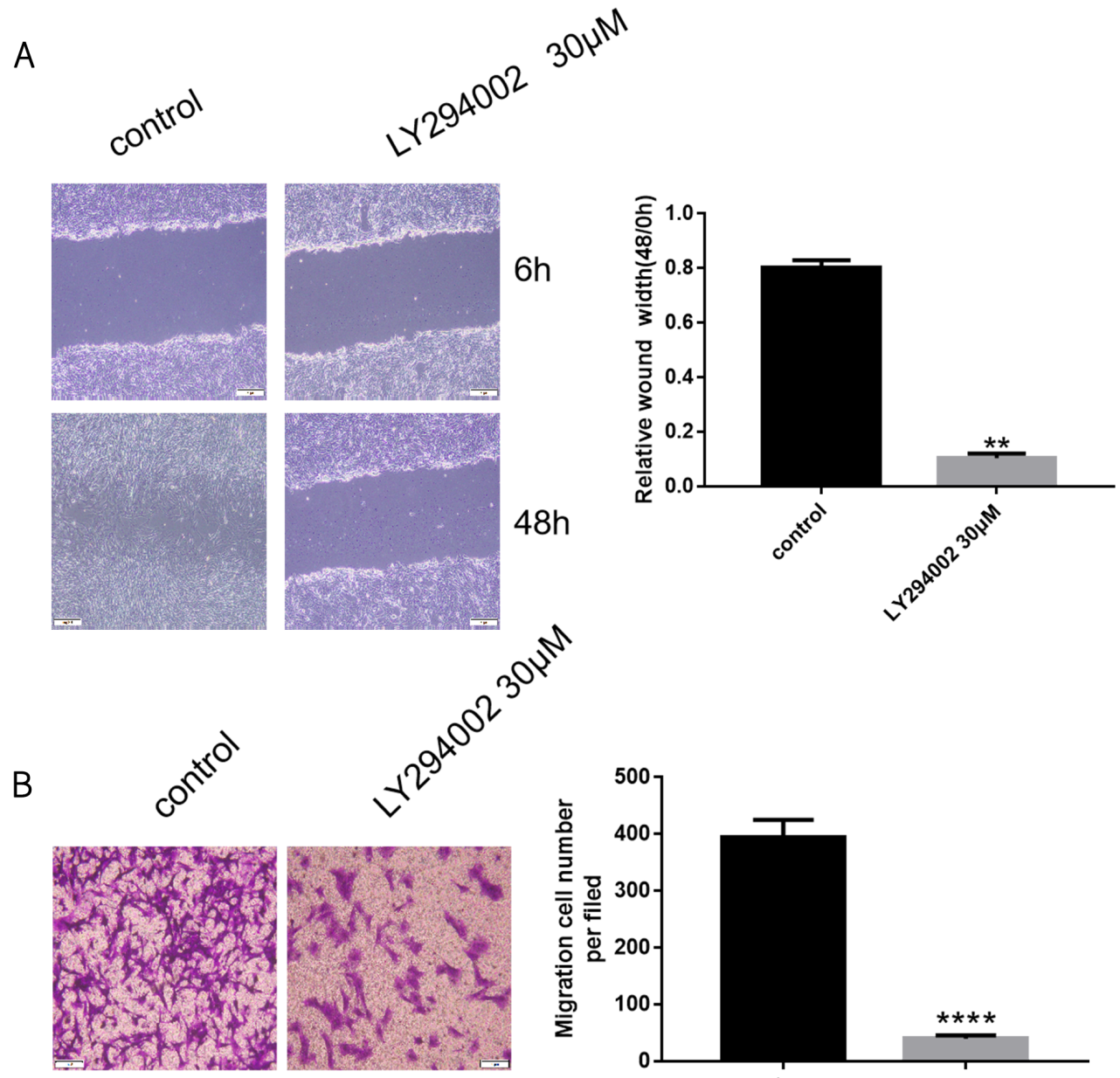

C
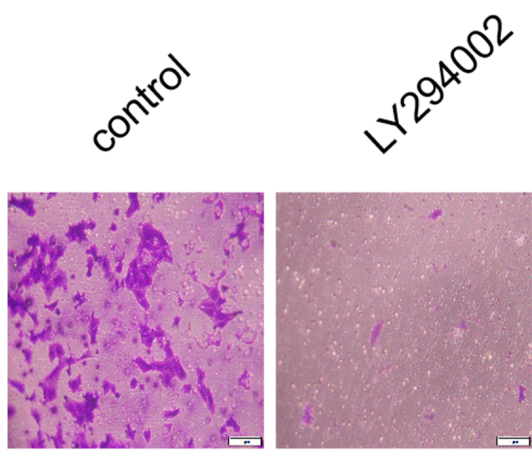<smiles>[Te][Te]</smiles>
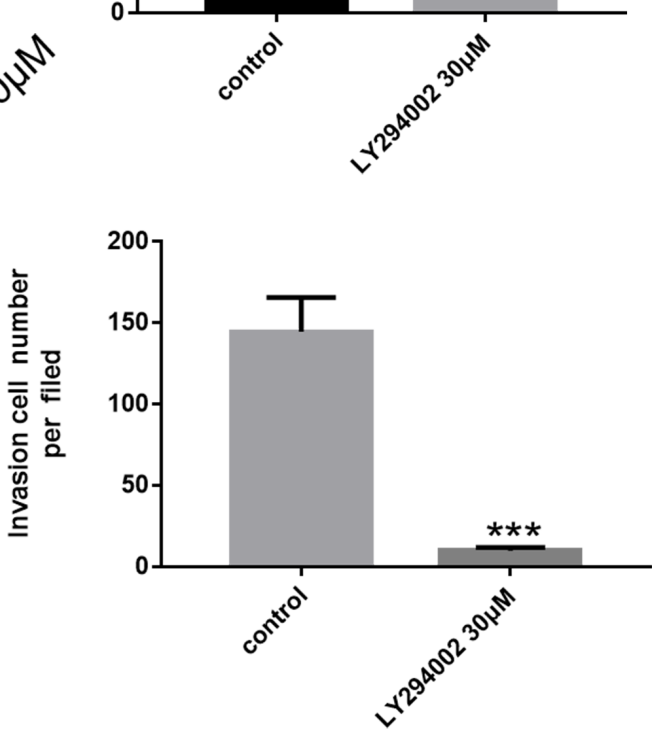

\section{Figure 6}

The influence of LY294002 on the migration and invasion of PCPs cells.Cells were treated with 30um LY294002 for24 h,wound healing \transwell assay was used to detect the changes of PCPs cells migration and invasion capacity(magnification, $x 200),(A, B, C) .(* \star \star p<0.001 ; * \star p<0.01 ; * p<0.05)$. 